cases where medicinal and expectant treatment will probably lose from 50 to 95 per cent., or more. Perhaps the battle of medical versus surgical treatment has been fought most vigorously over cases of appendicitis. I find that surgeons are becoming more and more convinced that the mortality would be diminished if all cases were operated on as soon as the diagnosis is tolerably certain. Mayo Robson says : It may seem somewhat radical, but I speak from conviction after consi-
derable experience, when I say that I believe the early operation underderable experience, when I say that I believe the early operation underMcBurney, would lead to a far greater percentage of recoveries than the Method of individualising which we in England generally adopt.

The points that we should impress upon ourselves are these : Let us try at once to make as accurate a diagnosis as possible. If the diagnosis makes it probable that the case is one of the class to which I have alluded, where the best chance for the patient is surgical interference, let a surgeon see the case without delay, and before any strong drug treatment is carried out unless the pain makes it necessary to give onefilth or one-fourth of a grain of morphine. If that is done then the best time for the surgeon to see the case if it can wait would be about four hours after the morphine, and he should come prepared to operate, if necessary, then and there. Mayo Kobson, in a paper on The Dangers of Delay, says :

Perhaps in no class of cases is delay in surgery attended with so much danger as in abdominal diseases $\ldots \ldots$. Thold that every case of intestinal obstruction is a case stage by a surgeon, not necessarily for operation, but that he may be prepared to interlere as soon as ordinary remedies have falled, and berore the system has become poisoned by the fermenting contents of diagnosis of the nature and seat of obstruction can be more easily made out.

I must again quote freely from Charters Symonds's paper:

Suppose we are called in at the period of onset and cannot decide between the perforative class and the colics, what is our best line of action? If the pain be moderate and subsiding, the best plan is to apply hot fomentations and dispense with sedatives, give no medicine of any kind, and make a second visit in four hours or less. The importance of this early second visit cannot be over-estimated. Over and over again a patient has been ordered a purge for an apparent attack of colic at the first visit, and at the second a graver diagnosis has had to be made. Having given a hypodermic injection, if necessary, we enter upon the second stage of the case. Repose follows, and everything depends upon the accurate observation of symptoms and the correct use of sedatives. No words are too strong in which to condemn the prescription of opium to be given by an attendant at regular intervals. The only safe plan, and one I would urge as a routine practice, is to give the sedative when the visit is made. We can time the second visit to see our patient free from of repose has set in. When a second dose is required after twelve, or still more after twenty-four, hours the case looks serious, and we can put, aside many possibilities. How may we know that a case is doing well? aside many possibilities. How mas we know that a case is doing wein? signs but may be a misguiding one. The pulse is better and tenderness diminished. In appendix cases there will be diminution of distension, we can locall perature will be lower. The patient does not require any further sedative, sickness has enemat or the formation of a local absess, giving plenty of to direct treationt. able of early signs is the general distension of the abdomen, then tenderness, the absence of local swelling and of local dulness, with rise of temperature and pilse. In perforating gastric ulcer, if we cannot form an opinion at the peritonitis.

Paralytic Distension.-I wish to speak now more in detail of paralytic distension, its prevention and treatment. A patient with slight peritonitis from any cause whatsoever may gradually develop general distension, and vomiting, and constipation. A patient liable to constipation may in one of his attacks be much more constipated than usual, and gradually general distension and vomiting develop. A cuse of abdominal section, quite simple and apparently quite successful, may, at any time from the second to the tenth day, develop the same symptoms. Now, if unrelieved, all these cases will die, the symptoms increasing, and fatal collapse coming on remarkably rapidly at the end. I know of no more disappointing termination to an apparently quite successful abdominal operation. These symptoms must, therefore, always be looked out for most carefully. They are most to be dreaded in patients who have previously been habitually constipated. I find surgeons are getting in the way of ordering an aperient as parly as the first or second night after the operation. Every day, in cases where this condition may arise, feel the pit of the stomach to make sure there is no undue tympanites. At the first sign of this try to get a free action of the bowels at once; calomel is probably the most satisfactory aperient to give. Five grains in a severe case, followed by a castor-ail enema, and a long flatulence tube. As soon as vomiting sets in stop all feeding by the mouth absolutely, and feed entirely by rectal enemata 4 ounces every four hours, only allowing the patient to rinse the mouth out with water not to be swallowed. By adopting these methods promptly at the first sign of danger the patient's life may be saved.

Surgical Treatment. - There is no need for me now to go into the details of surgical treatment; but I may just allude to some guiding principles. For instance, in intraperitoneal hæmorrhage it is best to wash out the peritoneal cavity with warm saline solution, the clots being better removed by washing out than sponging. For general suppurative peritonitis use the same method or a weak solution of boracic acid. In localised septic cases do not wash out the cavity, but sponge and mop out the infected region. In great distension of the bowel do not be satisfied with simply relieving the obstruction and closing up the wound, but always incise the bowel above the obstruction and empty it as far as possible, drawing it out and passing it through the hand if necessary, as that will cause it to contract better. In all cases of abdominal operation operate quickly but carefully. Take special precautions against shock and chill. Use hot bottles between the legs, have the room warm, have an enema of brandy and hot water ready to give at once if necessary; have a hypodermic injection of strychnine ready, and if it seems advisable leave half a pint of saline solution in the peritoneal cavity.

$$
1 \text { Address before the Hunterian Society. }
$$

\section{MIDLAND BRANCH.}

\section{THE LESSONS OF THE CRIMEAN WAR.}

By Ed. M. Wrench, F.R.C.S., V.D.

Surgeon Lt.-Colonel end V.B. Sherwood Foresters.

THE Crimean campaign was described by the pioneer of war correspondents (Dr. Russell) as " the most ruinous, most cruel, and least justifiable of all modern campaigns." Of the vast host of over a million men that for nearly two years fought for the occupation of the beautiful harbour of Sebastopol, I possess the qualification of being one of the now comparatively few survivors, and I trust that the narrative of some of my personal experiences may be interesting, and, though egotistical, help to explain why the Crimean war has left such an indelible mark on the minds of those who were youths in the Fifties. Although the medical establishment of the army was considerably increased when war was declared in the spring of 1854 , the mortality from battle (nine surgeons were killed in the campaign), and disease from overwork, was so alarming that in the autumn surgeons were hurried to the East as rapidly as possible.

I obtained my nomination on Monday, was examined on Tuesday, and started for the Crimea on Friday. I arrived there a few days after the hurricane in November to find the harbour of Balaclava strewn with the wrecks of 17 ships, and was immediately placed in charge of a ward in the hospital located in the Russian Military School, a substantial building, but quite devoid of hospital conveniences, and with every window destroyed by the recent hurricane.

I had charge of from 20 to 30 patients, wounded from Inkermann, mixed with cases of cholera, dysentery, and fever. There were no bedsteads or proper bedding. The.patients lay in their clothes on the floor, which from the rain blown through the open windows, and the traffic to and from the open-air latrines, was as muddy as a country road.

There were no nurses, no washing conveniences, either personal or for clothing. Two old soldiers, called orderlies, did their ignorant best to attend to the wants of the patients, but were chiefly occupied in rude cooking and burying the dead.

There was no bread except hard ship's biscuit-of course no milk. I cannot remember if there was any tea, but I believe not, only the famous green coffee. There was certainly no beef tea. Liebig's extract, and the substitutes of the 
present day, had not then been invented, and tinned meat was not procurable.

About midday a large iron witches' cauldron was carried into the middle of the ward, and the patients crowded round to dip in their tin canteens, the bedridden dependent on the generosity of their comrades for a share of the contents of the pot, which for all we knew might have been composed of the proverbial witches' broth, the cooks being so hard up that I should not like to say what they put into the stew. I remember that the sheep set aside on one occasion as suitable for the dinner of the seven surgeons was so like a skinned greyhound that we threw it on the roof, and ate salt pork (of which there was always abundance) instead.

Notwithstanding all these shortcomings of the commisariat, each surgeon had to make out a daily diet roll with the pretentious headings-Milk, Fish, or Full Diet-to satisfy the red-tape system, and prevent the purveyor being surcharged for the scanty food he was able to supply.

We were practically without medicines; the supply landed at the commencement of the campaign was exhausted, and the reserve had gone to the bottom of the sea, with the winter clothing (and several surgeons) in the wreck of the large steamer (the Prince) so that in November, 1854 , even the base hospital at Balaclava was devoid of opium, quinine, ammonia, and indeed of all important drugs. Sanitary science was then in its infancy, and sanitary precautions were not capable of being carried out, when the living were so hard pressed to live, and dead men were floating about among the ships at Balaclava harbour like dead cats in a canal. You will not be surprised to hear that many of our patients died, but even they were more lucky than the wounded Russians in another building in the town. where hospital gangrene carried off', I believe, every one, which sad termination to his devoted labours young Hervey Ludlow - the surgeon in charge-took go deeply to heart that he died from overwork and ex-

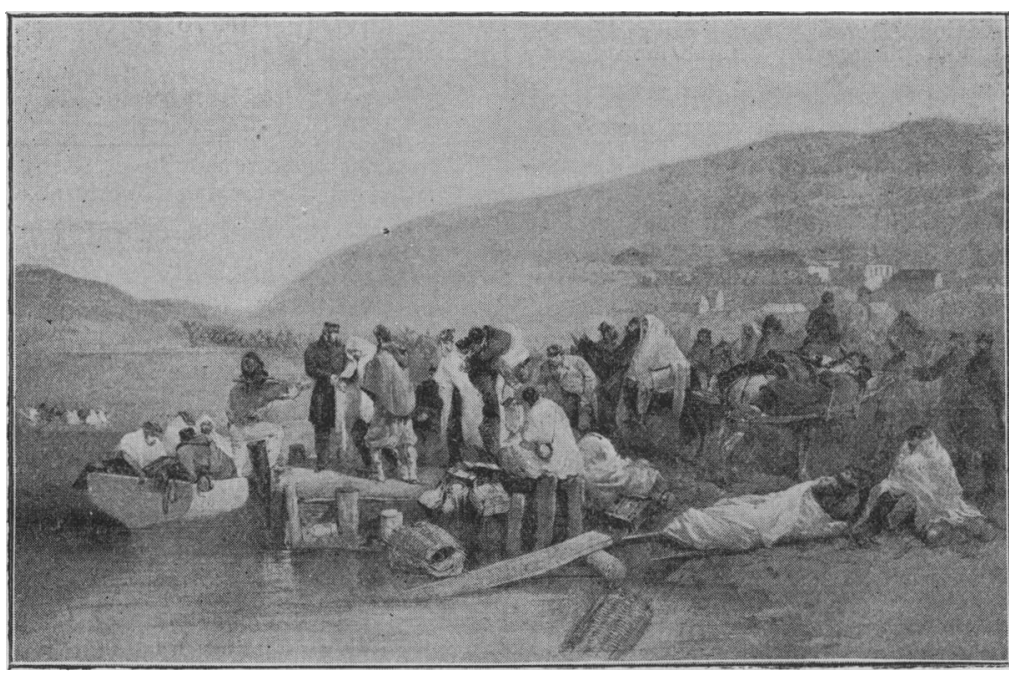

Fig. 1.-Embarkation of the sick at Balaclava. [From a sketch by Mr. William Simpson.]
It was the rule in most regiments to send the sick and wounded from their regimental hospital tents to Balaclava for embarkation to Scutari, whenever transport was available. The Eng!ish army being, however, unprovided with ambulance train, was dependent for the removal of their sick on the loan of the French mule litters, a mode of carrying the sick which they had invented in their recent Algerian campaigns.

I had not been many days in camp when I was placed in command of one of these convoys. I was permitted to ride the hospital mule on a wooden pack saddle without stirrups, and with a bottle of rum in each holster. I was instructed to, if possible, prevent any of the 300 sick from dying during the seven-mile journey. The ground was covered with snow, the wretched patients, wounded, frost bitten, and fever stricken, and scarce clothed, many of them being without boots or stockings, were strapped in seats on either side of mules, except a few too ill to sit up, who were laid in the bottom of one of our ammunition waggons, but these never reached Balaclava, for though provided with eight horses the waggon had not gone far before one and then another of the horses fell dead, and the remainder of the team were too weak to drag the waggon, so returned to camp.

My sufferings on the wooden pack saddle were not slight, but were not to be compared to those of the wretched patients, jolted and tossed about by the mules on the mountain paths, the short road to Balaclava across the famous battlefield being then considered unsafe.

Several mules fell, and one poor soldier recovering from a bullet through his chest was thrown out and crimsoned the snow from his reopened wound. I rode from end to end of the sad procession, now curbing the hurry of the French drivers anxious to get through their unpleasant duties, and then encouraging the sick, and supplying those who looked faint and likely to die with a suck from the neck of the rum bottle.

I am happy to say I

He was, however, the exception, for most of the young surgeons possessed the secret of health-light hearts and good digestion-and instead of being depressed or miserable, indulged, when off duty, in practical jokes on one another, and believed each week that Sebastopol would be captured in the next; an opinion, I may remark, shared by the rank and file all through that terrible winter: We should have had better reasion for our belief had we known that the Russians (except that they had roofs over their heads) were suffering from scanty food and disease as badly as ourselves. But, as Napoleon remarked in one of his Austrian campaigns, "in war you see your own troubles ; those of the enemy you cannot see."

The Russians had no special correspondents with their army, and it was many years before the sufferings and losses on their side were published, and they owned to the loss of half a million of men in the campaign. Early in December I was ordered up to "the front," as the line of camps in rear of the trenches was called. As I trudged up, carrying all my kit on my back, I net the mud-stained troopers of the IIth Hussars leading their horses, which were too weak to carry them, down to Balaclava to gave them from starvation by feeding them on the hay washed out of the wrecked transports on the shore of the harioour. For the next nine months took my share of the danger.uns and laborious trench duty, which I shall presently describe. handed them all alive to the care of the surgeon in charge of the sick wharf at the head of Balaclava Harbour, and there my responsibility ended. But alas! that was not the end of my poor patients' sufferings, for, from the scarcity of boats, it is not unlikely that many of them lay for several hours on the wharf before they could be put on board the ships that were to convey them to Scutari.

The ships were often sailing ships, devoid of all convenience for the sick; the voyage was tedious and the mortality great, and it is well known that ro per crint. of those embarked were thrown overboard before the vessels arrived at Scutari. Nor were the dangers then over, for the great hospital was infested with typhoid, and hence many finished their journey beneath the grand cypress trees in the beautiful cemetery overlooking the Bosphorus. than this to tell what surprised me as much on the night after I had taken the sick oonvoy to Balaclava in December, 1854 , as it will do you to hear it in 1899 . I was called to the lines of the 28 th Regiment, only a few hundred yards in rear of the trenches, and truly under fire of the Russian guns-for they occasionally sent a shot into camp-and in a bell tent, with the patient on the ground, I delivered a soldier's wife of a living child. The regiment had allowed a few of the women-chosen because they had been married several years
I do not know that I can find a better place in my story 
and had no family-to accompany the regiment to the East to do the officers' washing; a regiment was like a family in those days.

The English trenches were divided into right and left attacks, separated by the deep Woronzoff Ravine. During the winter months one assistant surgeon (the full surgeon never went on trench duty) accompanied each trench guard, which was relieved every twelve hours, in each attack. When the winter was over the guard and medical officers remained on duty twenty - four hours, and as the trenches extended the number of assistantsurgeons was increased so that instead of two there were often a dozen on duty.

Until late in the siege no shelter was provided for the surgeons; they had to brave the elements as well as the shot and shell, and to attend to the wounded under extraordinary difficulties-often in rain or snow in a muddy ditch, where at night the feeble light of a horn lantern had to be used with care lest it should draw down the Russian fire. On one occasion a round shot killed two stretcher-bearers, and took off the leg of the patient while the surgeon was dressing him for a previous wound.

I was on duty in the right attack at both the assaults on the Malakoff and Redan. The sight of the French swarming into the Malakoff when Sebastopol fell on September 8th was one not to be forgotten. The first assault on June 18 th failed all along the line. The assaulting columns were mown down by the grape and canister shot before they reached the Russian batteries, and the few survivors had to retreat leaving all their dead and many of their wounded on the ground. Most of these were gradually carried under cover, that is, out of sight of the enemy, for in the most advanced trenches there was no real protection from heavy fire. I was for eight hours engaged dressing wounded in a recently captured Russian rifle pit, occasionally running out to attend to such as were too severely injured to be moved. Some, alas, lay so completely in the line of tire of both the Russian and our own batteries that neither friends nor foes could render them any assistance, so there they lay untended for fifty-two hours. And yet, after this terrible ordeal, I found one man of my regiment still alive when I was able to approach him under a flag of truce on the third day.

At midday up went the white flags, when the sudden silence of the cannonade, the safety as we ran through the long grass and flowers to meet the Russians, their cordial greetings, and the little civilities we exchanged with our enemies, made one ask oneself, "Am I dreaming?" Several of the Russian officers spoke English perfectly, and one chaffed me about the eccentricity of the colonel of my regiment, who having been some time before taken prisoner during a sortie, asked the Russians to demand a flag of truce to ascertain if a letter he had received from his wife, that he had not read, had been picked up alter the fight. The truce did not last muny minutes; we got back to our respective lines, the white flags were hauled down, and each side did their best to kill their recent iriends.

The regiment in which I was assistantsurgeon-the 34 th Foot - suffered so heavily during June, 1855 , that every captain was rendered hors de combat, and five line huts were converted into hospitals. Two of the four regimental surgeons knocked up, and in consequence it was not uncommon for wounded men to be several days before they got proper exkept with the regiment, and the results were very satisfactory. Microbes were then undreamt of, and every wound was septie, and many of them swarming with maggots. The older surgeons had a great dread of (the then recently invented) chloroform, fostered by the historical memorandum from the Director - General almost forbidding its use, and adding that the cries of the patient undergoing an operation were satisfactory to the surgeon, as an indication that there was no fear of syncope, and that pain was a stimulant that aided recovery.

We therefore only used chloroform for the more serious operations, and never to facilitate examination, or for what we considered trivial operations, as cutting out bullets or setting compound fractures. The hypodermic syringe was not yet invented. Notwithstanding all these disadvantages, our wounded did remarkably well. The huts and tents were situated on a breezy upland, and the weather then being we had no nurses, we had by that time trained the orderlies and we were able to procure abundance of fresh meat, and occasionally soft bread.

I shall probably be expected to make some remarks on the breakdown of the medical arrangements. From what $I$ have 
already described you will, I think, see that it was the system, and not the men, that failed. The medical department was, like every other in the army of that date, quite unprepared for a great and prolonged war, hampered by red tape, and denied all independence of action.

Miss Nightingale justly received great praise for the improvement she effected in the larger hospitals. Had the surgeons been given her power to obtain what they required regardless of cost, much of the misery and mortality in the hospitals would have been averted before her arrival.

The old regimental system of hospitals and medical officers was, and probably is, the best in time of peace, but it must break down in time of war. It is clearly better to practise in garrison what will have to be carried out in the field, than as Abraham Lincoln remarked, "have to swop horses when fording the stream.

The Crimean was the first war in which the special newspaper correspondent kept the public informed, not only of the valour of the troops and the losses in the battles, but also of the sufferings, the starvation, and the deaths-the result of ignorance, neglect, and unpreparedness. Hence the distress of the nation, which even now looks back on that time with horror.

Wars always have been and always will be cruel. It is, however, the pride of our profession that, while sharing the fatigues and dangers of the campaign, our sole duty will always be the protection of the soldier from what after all is his most deadly enemy-disease, and the alleviation of the sufferings of the wounded.

The Crimean campaign taught a lesson that I trust will never be forgotten by the nation, that unless the medical department of the army is made efficient, and supplied with its proper complement of officers and ambulance during peace it cannot be expected to do its duty efficiently during war.

\section{MEM ORAN DA:}

MEDICAL, SURGICAL, OBSTETRICAL, THERAPEUTICAL, PATHOLOGICAL, ETc.

\section{AN OUTBREAK OF FEVER ATTRIBUTED TO} MOSQUITOS

ON my voyage home from Calcutta last March, Mr. J. F. Parker, of Messrs. Thacker, Spink, and Co., of Calcutta, and Mrs. Parker, who were travelling in the same vessel with me volunteered the following statement regarding an outbreak of fever. I cannot answer for the facts, because I was not aware of the case at the time it occurred, and because a letter which I addressed to Calcutta on the subject appears to have miscarried; but Mr. and Mrs. Parker seemed to be so familiar with the circumstances, and to be so certain regarding those facts, that I think I may venture to record the case. If correct, it is an interesting instance of mosquito-borne malaria; if incorrect, I hope that publication will lead to the truth being known. I copy the statement just as it was written down from Mr. and Mrs. Parker's evidence in my notebook. They said :

The rst Calcutta Company of the Boys' Brigade went out to "camp" in the month of October, 1898 . They were given the use of one of the bungaRows in Barrackpore Park, fourteen miles from Calcutta. Barrackpore Park is the estate round Government House at Barrackpore; the bungalow referred to is one occasionally used by the Viceroy's staff; and is a brickby a verandure, soundly made, containing large rooms, and surrounded by a verandah. The water supply is the same as that of Calcutta. The kitchen is the Viceroy's kitchen. There are some ponds about the park and the river Hooghly flows close by. The party in "camp" consisted of three officers, all young men, and thirteen boys of between $x_{3}$ and 18 year of age. The officel's were Mr.- the captain, and Mr. and Mr.the two lieutenants. The whole party slept

During the week the party lived in the bangalow, the boys did not sleep under mosquito nets because it was feared the would tear them although the three officers did so. Mr. - (the captain) informed that mosquitos were very numerous, and that the boys were bitten by them. On the last day of the week a sister of one of the boys visited the camp, and was also bitten so much that her arm swelled; she was presen only in the day.

All the boys. were attacked by malarial fever within a few dass after the close of the camp. One died, and several were seriously ill. Three native servarts who went with the party were also, to our certain knowledge, taken ill, one, a boy, seriously. The two other servants were lent to the party by ourselves. The little girl just referred to was also attacked the day after her visit (?) The medical man attending the boys stated that the disease was malarial fever, and this was the disease entered on the death certificate of the one who died, named $M$. We heard that the boys had repeated attacks of shivering followed by fever. M. was the firs attacked (the day after returning), and all the rest were attacked within about ten days

The three officers (who slept in mosquito nets) remained perfectly well up to February 23 rd, 1899, when Mr. and Mrs. Parker left for England. The officers slept every night in the bungalow. A friend of the captain's, Mr. - also slept in the bungalow one night in a mosquito net, and was not attacked. The food of the whole party was precisely the same.

The three native servants, of course, did not sleep under mosquito nets. Thus, out of twenty-one persons concerned seventeen who did not use mosquito nets were all attacked with fever, while four who did use them all escaped.

Mr. and Mrs. Parker have authorised me to publish their names in connection with this case.

Liverpool.

Ronald Ross, D.P.H., M.R.C.S.

SPONTANEOUS EVOLUTION.

CAses of spontaneous evolution are, I think, of sufficient rarity to allow me to place the following on record. I was called in consultation to see a black woman, aged 21 , in her fourth pregnancy. The medical officer in attendance, Dr. Irving, had sent for me, as the right arm was presenting, and the cord was prolapsed. The woman had just been admitted and had been in labour for about twelve hours. I had the patient put under chloroform with a view to turning, but on examination I found the right side of the chest almost at the vulvar orifice, and the trunk descending into the unusually roomy pelvis. The placenta was covering the right shoulder posteriorly. The head, face forwards, was in the right iliac fossa. Dilatation was complete. The lower limbs were extended at the knee, and flexed at the hip in front of the trunk.

There being, in my opinion, ample room, I determined to assist evolution, which I easily accomplished by traction on the lower end of the trunk. The shoulder remaining under the symphysis, the breech descended and swept along the concavity of the sacrum. Rotation of the head then took place from right to left, bringing the occiput forwards. I had to apply very little force, and I think that probably Nature would have succeeded unaided in accomplishing delivery if the case had been left. The child was a well-grown female at full term, but was, of course, dead.

Public Hospital, George Town, Demerara

\section{Walter S. Barnes.}

\section{REPORTS}

ON

\section{MEDICAL AND SURGICAL PRACTICE IN THE HOSPITALS AND ASYLUMS OF THE BRITISH EMPIRE.}

COROSAL HOSPITAL, BRITISH HONDURAS.

AN UNUSUALLY LARGE LIVER ABSCESS : OPERATION : RECOVERY.

[By P. T. Carpenter, M.R.C.S.Eng., of the Colonial Medical Service.]

W. C., a Jamaican, aged 40, was admitted into the Corosa Hospital at 6 P.M. on August 7 th, 1898 , complaining of a very painful swelling in the pit of the stomach. He was an old soldier, having served on the West Coast of Africa and on various stations in the West Indies. Since he left the army, ten years before, he had led a debauched life, but had never been seriously ill until last year, when he suffered from a bad attack of dysentery. From this he completely recovered, and remained well until February, 1898 , when a severe pain in the lumbar region developed, which has continued. At the beginning of August, 1898, he noticed a swelling above the navel which was becoming more and more painful.

His general condition on admission a week later, except for the very painful lump in the epigastrium, was not serious, although the temperature was $102^{\circ} \mathrm{F}$. There was no jaundice. The tumour was found to be about the size of a full-grown fotal head, and projected prominently in the epigastric region, filling the space between the ensiform cartilage and the umbilicus, and extending from side to side as far as the 